\title{
ILLUSTRATIONS
}

\section{SDS ACTIVISTS}

(following p. 96)

Vivian Rothstein at a Trade Union Federation meeting in Vietnam, 1967

Vivian Rothstein at the dedication of Transitional Housing, 1996

Bernardine Dohrn in 1970

Bernardine Dohrn in 1995

John Brown Childs in 1964

John Brown Childs marching in support of United Farm

Workers in Watsonville, 1997

Jeanne Friedman at the Indochinese Women's Conference in Canada, $197 \mathrm{r}$

Jeanne Friedman in 1997

Terry Koch in 1965

Terry Koch in 1997

Dorothy Burlage with Robb Burlage during the 1960 s

Dorothy Burlage in the $\mathrm{r} 990 \mathrm{~s}$

Michael Kazin in 1971 
Michael Kazin in 1998

Naomi Schapiro in I971

Naomi Schapiro and her family in 1997

Jim Shoch at a political meeting in the r $960 \mathrm{~s}$

Jim Shoch in 1998

\section{YAF ACTIVISTS}

(following p. 238)

Mike and Kit Thompson with Senator Barry Goldwater, $x 976$

Mike Thompson in the I990s

Emmy Lewis campaigning for Goldwater, 1964

Emmy Lewis meeting with President Reagan, 1995

Harvey Hukari speaking at a student government hearing in the 1960 s

Harvey Hukari in the r 990 s

Sharon Presley in 1965

Sharon Presley in the I 990 S

Louise Lacey in 1966

Louise Lacey in the r 990 s

Lee and Anne Edwards in 1968

Lee Edwards with President Reagan, 198 I

Anne Edwards with Speaker of the House Newt Gingrich, 1996

Allen Brandstater introducing then-governor Ronald Reagan at YAF's I968 California convention

Allen Brandstater in the 1990 s

Kathy Rothschild protesting against IBM in St. Louis, 1968

Kathy Rothschild with her husband, Rick, in 1998

Dave Schumacher attending a conference on "Overcoming World Hunger," 1969

Dave Schumacher with Karl Hess during a retreat in Fort Collins, Colorado, I987

Dave Schumacher in the I990s 